\title{
Neural tube defects in a country town Confirmation of clustering within a particularly small area
}

\author{
M. J. AYLETT,1 C. J. ROBERTS² AND S. LLOYD2 \\ The Surgery, High Street, Corsham, Wilts ${ }^{1}$ and Department of Social and Occupational Medicine, The Welsh National \\ School of Medicine, Cardiff ${ }^{2}$
}

\section{SUMMARY}

Eighteen infants with neural tube defects occurring in 979 births over five years in a small Wiltshire town were investigated for evidence of spatial epidemicity. Applying a method not used previously in the study of these defects, clustering was confirmed, a critical distance between cases of up to 100 metres giving a highly significant result $(P=0.001)$, and with one exception the observed number of pairs significantly exceeds the expected number $(P<0.01)$ even up to 1,000 metres.

\section{INTRODUCTION}

In order to study the spatial distribution of relatively uncommon conditions it is usually necessary to collect cases from a wide area (e.g., a region) and, if a smaller unit of space is used (say a county borough), the time period for collection has to be extended in order to accumulate a sufficient number of cases to give a stable incidence rate. These constraints put the investigator at some disadvantage since the wider he has to cast his net in space or in time the more his confidence is undermined that his comparison groups are similar in all respects apart from the one under investigation, thus limiting the inferences he can make from his findings. Ideally, spatial behaviour should be examined within subdivisions of a reasonably homogeneous area whose demographic and social characteristics are well known to the investigator, for example, electoral ward comparisons within a town. But how can 'low intensity epidemicity' in space such as this be studied without waiting a long time for a sufficiently large number of cases to accumulate?

In 1963 Knox suggested that this difficulty could be overcome for studies of spatial and temporal behaviour together and he published a test of space-time clustering which allowed the joint space-time relationship of small numbers of cases to be investigated. Since then this method has been applied to various disorders, including leukaemia, Hodgkin's disease, Down's syndrome, and cleft palate. Trichopoulos, Desmond, Yen, and MacMahon (1971) reported no evidence of space-time clustering in anencephaly and spina bifida in a sample of 1,003 affected infants born in Rhode Island between 1936 and 1965. Fedrick and Wilson (1971) looked for evidence of space-time clustering of abnormalities occurring in Glasgow from 1964 to 1968, comparing the index cases with an unmatched $5 \%$ random sample of all births. They found significant clustering of hydrocephalus but not of anencephalus or spina bifida. Siemiatycki and McDonald (1972) similarly investigated cases from 1956 to 1965 in Quebec with inconclusive results. Knox's method, however, does not allow the spatial behaviour to be studied separately from temporal behaviour, and thus to date the spatial distribution of neural tube defects in small well-defined 'homogeneous' communities has never been subjected to any tests of mathematical probability in order to ascertain if their distribution is non-random. There have, however, been frequent subjective impressions of spatial clustering in small communities, in particular in the reports of Polman (1951), Pleydell (1960), Boris, Blumberg, Feldman, and Sellers (1963), Laurence, Carter, and David (1967), Spellman (1969), Flynt (1970), and Aylett (1973).

In 1973 Lloyd and Roberts published a test specifically for spatial clustering of low-intensity epidemicity (the test is essentially a modification of Knox's method) and they applied it to 57 congenital limb defects born in Cardiff between 1964 and 1966. The present paper attempts to validate Aylett's subjective claim that the neural tube defects born in the Corsham area between 1968 and 1972 exhibited spatial epidemicity by applying an objective test (Lloyd and Roberts, 1973) to his original data. 


\section{Material AND Methods}

Aylett (1973) reported the birth of 18 infants during the period 1968-72 inclusive in the rural town of Corsham. These cases consisted of five anencephalics, one of which also had spina bifida, 12 with spina bifida, seven of these also having hydrocephaly, and one with hydrocephaly alone. This represented an incidence of 19.8 per 1,000 births, a figure higher than any previously recorded.

The study area measured 10 square miles and was defined using the Registrar General's Census Enumerating Districts. This allowed demographic comparisons to be made which confirmed that the study area had a birth rate, maternal age, and parity distribution similar to the south-west region of England and Wales. There were, however, a higher proportion of social class III and a lower proportion of social classes IV and V in the study area compared with the south-west region as a whole. During the five-year period of the study (1968-72) there were 979 births. Aylett had good reason to believe that his case finding was complete but in any event the loss of one or two cases would not invalidate the ensuing statistical analysis of spatial clustering.

A list of all births occurring in the study period to mothers residing within the area at the time of their confinement was prepared from the County Medical Officer's records, which included details of birth date, place of birth, maternal age, parity, and address at the time of birth. Local birth registers then provided details of fathers' occupations from which social class groups were allocated. Five controls were then matched against each index case for maternal age, parity, social class, and time of birth. The co-ordinates of the addresses of both cases and controls were recorded as eight-figure map references. Detailed knowledge of the locality enabled accurate pin-pointing of these references (to within 10 metres) from six inches to one mile Ordnance Survey maps.
The distribution of distances for all possible pairs was obtained for each set of cases as in Knox's method, and the number of pairs within various distance criteria was compared with the mean number of pairs satisfying the same criteria from the random sample.

\section{RESULTS}

The number of pairs less than specified distances derived from the frequency distribution of all possible pairs of neural tube defects in the random samples is shown in Table $I$, and significance values have been applied for various critical differences to the differences between the observed number of neural tube defect pairs and the number expected from randomly selected matched controls. A critical distance between cases of up to 100 metres gives a highly significant result $(P=0.001)$ and with one exception the observed number of pairs significantly exceeds the expected number even up to 1,000 metres. These results are summarized in Table II. Beyond 2,000 metres the results no longer achieve significance.

\section{Discussion}

The results of this study would appear to confirmt Aylett's original subjective impression that this was a local epidemic of neural tube defects, and as far. as we are aware this is the first time that spatial epidemicity in a small community has been demonstrated statistically. The most likely explanation of this finding is that families with similar genes or religious, cultural or other common interests are more likely to live closer to one another than those with no ethnic ties.

However, examination of the ethnic background of the study population revealed that it was exclusively Anglo-Saxon apart from one Asian and two West Indian families whose offspring did not comprise any of the case group. Possible blood

TABLE I

FREQUENCY DISTRIBUTION OF ALL POSSIBLE PAIRS (NEURAL TUBE DEFECTS AND RANDOM SAMPLES) BY DISTANCE

\begin{tabular}{|c|c|c|c|c|c|c|c|c|c|c|c|}
\hline & \multicolumn{10}{|c|}{ Distance Intervals (metres) } & \multirow[b]{2}{*}{ Total } \\
\hline & $\begin{array}{l}\text { Up to } \\
100\end{array}$ & $\frac{100-}{249}$ & $250-$ & $\begin{array}{c}500- \\
749\end{array}$ & $\begin{array}{c}750- \\
999\end{array}$ & $\begin{array}{c}1000- \\
1499\end{array}$ & $\begin{array}{c}1500- \\
1999\end{array}$ & $2000-$ & $\begin{array}{r}2500- \\
2999\end{array}$ & $\begin{array}{c}3000 \\
\text { and over }\end{array}$ & \\
\hline Cases & 10 & 8 & 8 & 29 & 14 & 38 & 16 & 13 & 9 & 8 & 153 \\
\hline 1 & 3 & 7 & 9 & 14 & 13 & 42 & 42 & 6 & 13 & 4 & 153 \\
\hline 2 & 1 & 8 & 14 & 17 & 22 & 47 & 29 & 9 & 4 & 2 & 153 \\
\hline 3 & 1 & 9 & 8 & 15 & 9 & 35 & 30 & 19 & 9 & 19 & 153 \\
\hline 4 & 2 & 5 & 6 & 19 & 18 & 30 & 27 & 23 & 19 & 4 & 153 \\
\hline 5 & 4 & 5 & 10 & 20 & 12 & 42 & 31 & 11 & 9 & 9 & 153 \\
\hline
\end{tabular}


TABLE II

NUMBERS OF PAIRS BY CRITICAL DISTANCE AND THEIR SIGNIFICANCE VALUES

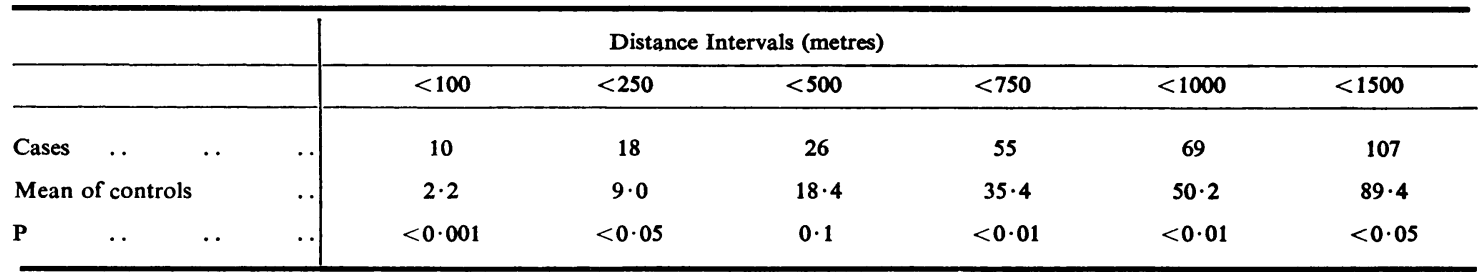

Significance values are based on a Poisson distribution for the first distance and $\chi^{2}$ with Yates's correction for the remainder

relationships between the index cases were excluded by a study of their names and maiden names and the origin of their families. There was no evidence that the case group comprised individuals who were the offspring of intermarriages between members of the indigenous population, and nearly all the grandparents of the above cases were immigrants from other parts of England. We are of the view then that genetic or ethnic factors are not the explanation of the spatial clustering observed in the present study. Furthermore, the strict matching of controls for social class, parity, maternal age, and month of birth almost certainly means that these factors (and other factors closely associated with them) are not the cause of this phenomenon. There remains, therefore, the real possibility that within this area some environmental factor, as yet unrecognized, is causing a spatial clustering of neural tube defects.

However, our results could just possibly be the one chance in a thousand occurrence predicted by the statistical analysis, and this can be refuted only by the confirmation of this finding in other communities. But in the meanwhile this new observation must rekindle optimism that the distribution of neural tube defects is under some eavironmental influence and that, theoretically at least, the problem is still open to some form of preventive measure once the factor has been determined.

This research was supported by a grant from the Research Foundation of the Royal College of General Practitioners. We gratefully acknowledge the help given by Dr. C. D. L. Lycett, County Medical Officer of Health, and Mr. R. O. Calver, County Statistician, Wiltshire County Council and also of the Registrars of Births, particularly Mr. A. J. Wilson and Mrs. Woodman of his department, in the collection of birth data. Dr. J. A. C. Weatherall, of the Medical Statistics Division of the Office of Population Censuses and Surveys, also kindly gave us advice and information. We wish to thank Mrs. Carole Hood for organising and painstakingly collating all the information on the normal births.

\section{REFERENCES}

Aylett, M. J. (1973). Spina bifida in general practice. Practitioner, 211, 75.

Boris, M., Blumberg, R., Feldman, D. B., and Sellers, T. F. (1963). Increased incidence of meningomyeloceles. J. Amer. med. Ass., 184, 768.

FEDRICK, J. and WiLson, T. S. (1971). Malformations of the central nervous system in Glasgow. An examination of the evidence for clustering in space and time. Brit. J. prev. soc. Med., 25, 210.

FLYNT, J. W. (1970). An unusual incidence of central nervous system defects in a military population. Abstract of a paper read at the 10th Annual Meeting of the Teratology Society. Teratology, 3, 199.

KNOX, G. (1963). Detection of low intensity epidemicity. Application to cleft lip and palate. Brit. J. prev. soc. Med., 17, 121.

Laurence, K. M., Carter, C. O., and David, P. A. (1967). Major central nervous system malformations in South Wales. I. Incidence, local variations and geographical factors. Brit. J. prev.soc. Med., 21, 146.

Lloyd, S. and RoberTs, C. J. (1973). A test for space clustering and its application to congenital limb defects in Cardiff. Brit. J. prev. soc. Med., 27, 188.

Pleydell, M. J. (1960). Anencephaly and other congenital abnormalities. An epidemiological study in Northamptonshire. Brit. med. J. 1, 309.

Polman, A. (1951). Anencephaly, spina bifida and hydrocephaly: a contribution to our knowledge of the causal genesis of congenital malformations. Genetica, 25, 29.

SiEmiatycki, J. and McDonald, A. D. (1972). Neural tube defects in Quebec. A search for evidence of 'clustering' in time and place. Brit. J. prev. soc. Med., 26, 10.

Spellman, M. P. (1969). Anencephaly, a five year survey in Cork. J. Irish med. Ass., 62, 316

Trichopoulos, D., Desmond, L., Yen, S., and MaCMAHON, B. (1971). A study of time-place clustering in anencephaly and spina bifida. Amer. J. Epidem., 94, 26. 